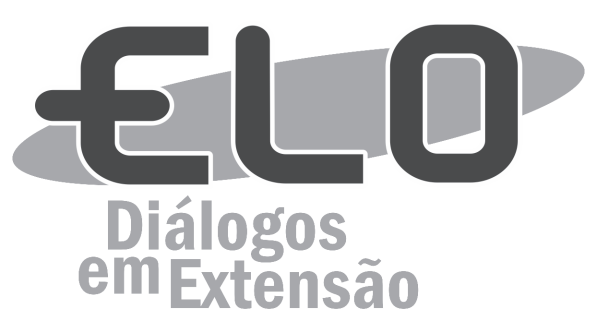

\title{
PET FEIRA-LIVRE: epidemiologia e saúde ambiental através das trocas de experiências com a comunidade de Florestal-MG
}

\author{
Mardem Michael Ferreira da Silva ${ }^{1}$, Ana Carolina de Stefano Pereira ${ }^{2}$, Laís Ferreira Silva ${ }^{3}$, \\ Dalila de Fátima Ferreira ${ }^{4}$, Marina Ferreira Silva ${ }^{5}$, João Paulo de Souza ${ }^{6}$
}

\begin{abstract}
Resumo: Este relato de experiência é resultado de uma atividade epidemiológica e de saúde ambiental desenvolvida pelo PET/EDUCAÇÃO da Universidade Federal de Viçosa, Campus Florestal-MG, com o título: "PET FEIRA-LIVRE". O projeto objetivou proporcionar a troca de saber científico e popular entre os alunos do programa PET/EDUCAÇÄO e a comunidade da cidade de Florestal-MG. O primeiro PET FEIRA-LIVRE foi realizado com o tema: Animais Peçonhentos. A intervenção aconteceu na feira livre da cidade de FlorestalMG, com a exposição de animais e aplicação de questionários para o público da feira por meio de método comparativo e, como metodologia utilizada, privilegiou-se a pesquisa-ação. Os resultados apontaram que as pessoas que tiveram acesso à tenda de animais peçonhentos identificaram com maior clareza quais animais possuem peçonha, em comparação aos que não tiveram acesso às informações da tenda. Conclui-se que a intervenção na feira livre da cidade de Florestal-MG, com o tema animais peçonhentos, contribuiu para a desmistificação de conceitos errôneos, tendo sido constatado que a realização desse evento contribuiu significativamente para o conhecimento a respeito do tema abordado.
\end{abstract}

Palavras-chave: Animais peçonhentos. Feira livre. Epidemiologia. Extensão universitária. Exposição. Saúde ambiental.

Área Temática: Educação, Meio ambiente, Saúde.

\section{PET FAIR-FREE: epidemiology and environmental health through the exchange of experiences with Florestal-MG community}

\begin{abstract}
This experience report is the result of an epidemiological and environmental health activity developed by PET/EDUCATION from Federal University of Viçosa, Campus Florestal-MG, entitled: "PET FAIR-FREE". The project aimed to provide the exchange of scientific and popular knowledge between students of PET/Education program and community of Florestal city. The first PET FAIR-FREE was performed with the theme: Venomous Animals. The intervention took place in the open fair in Florestal city, with the exhibition of animals and applications of questionnaires to the public of the fair, using the comparative method and as methodology utilized emphasis was placed on action research. The results showed that people who had access to tent with poisonous animals identified more clearly which animals have venom compared to those who did not have access to the information in tent. We conclude that the intervention in the free market in Florestal city, with the theme venomous animals, contributed to the debunking misconceptions, having been found that the event performed contributed significantly to the knowledge of the topic discussed.
\end{abstract}

\footnotetext{
${ }^{1}$ Graduando do curso Ciências Biológicas - UFV/CAF. Bolsista PET. mardemmichael@yahoo.com.br

${ }^{2}$ Bióloga, licenciada pela UFV/CAF. anacarolina_stefano@yahoo.com.br

${ }^{3}$ Graduando do curso de Ciências Biológicas - UFV/CAF. Bolsista PET. laís.ferreira@ufv.br

${ }^{4}$ Graduando do curso de Ciências Biológicas - UFV/CAF. dalilabio19@gmail.com

${ }^{5}$ Graduando do curso de Ciências Biológicas - UFV/CAF. marina.fsilva@hotmail.com

${ }^{6}$ Tutor do PET/EDUCAÇÃOUFV/CAF. joãopaulobio@hotmail.com
} 
Keywords: Epidemiology. Environmental health. Exposure. Poisonous animals. Street fair. University extension.

Thematic area: Education, Environment, Health.

\section{PET FEIRA-LIBRE: la epidemiología y la salud del medio ambiente a través del intercambio de experiencias con la comunidad Florestal-MG}

Resumen: En este trabajo se presenta el resultado de la experiencia de un evento epidemiológico y de salud ambiental desarrollada por el PET/Educación de la Universidad Federal de Viçosa, Campus Florestal-MG, con el título: "PET FERIA-LIBRE". Este proyecto se realizó con el objetivo de conceder un intercambio de conocimientos tanto científico como popular entre los alumnos del programa PET/EDUCAÇÃO y la comunidad de la ciudad de Florestal-MG. La primera PET FERIA-LIBRE fue desarrollada bajo el tema: Animales Ponzoñosos, participando de la feria libre con la exhibición de animales y el estudio de encuestas realizadas al público asistente de esta; por medio de la metodología búsqueda/acción y el análisis de datos a través del método comparativo se observó que las personas que tuvieron acceso al stand de animales ponzoñosos identificaron con mayor facilidad cuales de estos presentaban ponzoña, en comparación a los que no tuvieron acceso a la información. Se concluye que la intervención en la feria libre de la ciudad de Florestal-MG con el tema animales ponzoñosos contribuyo a la desmitificación de conceptos equivocados, constatando así, que la realización de este tipo de evento mejora significativamente el conocimiento frente al tema abordado.

Palabras clave: Animales ponzoñosos. Epidemiología. Exposición. Extensión universitaria. Feria libre. Salud ambiental.

Áreas Temática: Educación, Medio ambiente, Salud.

\section{Introdução}

A Universidade ocupa um papel muito importante na mediação entre a sociedade e o conhecimento científico produzido. Nos últimos tempos, além do papel de ensinar e pesquisar, acrescentou-se às instituições universitárias a função de fazer ações de extensão, como sendo uma forma de abertura mais ampla à sociedade (SILVA, 2003). Assim, as ações das Universidades Públicas Brasileiras são pautadas em um tripé: ensino, pesquisa e extensão.

A extensão universitária é caracterizada segundo FREIRE (2006) pela comunicação prática entre a Instituição de Ensino Superior e a comunidade do entorno, sendo observados diálogos mútuos que contribuam para a troca de experiências e permitam ações concretas dentro de uma dada realidade, causando a transformação de questões sociais. Dessa forma, as atividades extensionistas buscam um ideal de transformação da realidade social, que através de suas práticas promovam a difusão da ciência e a troca de conhecimentos, podendo estas também oferecer cultura e lazer para uma comunidade (RONZELI JÚNIOR, 2003).

Conhecendo a importância das atividades de extensão, um grupo de estudantes vinculados ao PET/EDUCAÇÃO do Campus Florestal-MG da Universidade Federal de Viçosa, iniciou um trabalho de extensão, denominado PET FEIRA-LIVRE. O intuito geral desse projeto é promover a abordagem de temas transversais junto à comunidade por meio da utilização do espaço da feira livre da cidade de Florestal-MG. Em razão das características singulares encontradas no PET/EDUCAÇÃO - UFV/ Florestal, que abrange alunos dos cursos de licenciatura da UFV/Florestal, o PET FEIRA-LIVRE pode levar informações diversas à população Florestalense e realizar trocas de experiências nas áreas das Ciências Biológicas, Educação Física, Física, Matemática e Química.

Em virtude da singularidade das ações extensionistas, os temas trabalhados, podem gerar ações que visam melhorar a qualidade de vida das pessoas. Nesse sentido, atividades envolvendo educação ambiental e epidemiologia melhoram a percepção dos membros da sociedade sobre a biodiversidade (QUIRINO et al.,2009) e métodos de prevenção contra acidentes com animais peçonhentos (MOURA et al., 2010). Os acidentes com animais peçonhentos têm aumentado muito, principalmente, na zonal rural das cidades (OLIVEIRA, COSTA \& SASSI, 2013), sendo que as alterações nos ambientes naturais são a principal causa da entrada desses animais no ambiente urbano (LIMA et al., 2009). Outro fator, não menos importante, é o extermínio indiscriminado de animais por causa da falta de conhecimento (BAPTISTA et al., 2008). Assim, tornam-se importantes trabalhos com objetivo de conscientizar a 
sociedade com atividades de educação promovendo a sustentabilidade ambiental e a prevenção de acidentes com animais peçonhentos (QUIRINO et al., 2009).

O município de Florestal-MG integra a Região Metropolitana de Belo Horizonte, estando a uma distância de 65 quilômetros da capital, com uma população de cerca de 6.600 habitantes, de acordo com dados do censo (IBGE, 2010). A feira livre, nesse município, funciona principalmente como mercado para a comercialização de artesanatos e comidas típicas produzidas por feirantes moradores do município, bem como espaço para divulgação e democratização da cultura, seja por meio da música, da dança ou do teatro. A feira livre foi escolhida como instrumento deste projeto em função do fato de apresentar uma alta sociabilidade, sendo esse espaço público um local privilegiado para a troca de experiências. Por ser um espaço sociável, esse tipo de evento maximiza o alcance da atividade extensionista (MASCARENHAS \& DOLZANI, 2008).

O objetivo principal do primeiro evento relacionado ao projeto PET FEIRA-LIVRE foi de oferecer à comunidade Florestalense informações sobre o tema: Animais Peçonhentos e propiciar aos alunos do PET/EDUCAÇÃO a vivência da prática extensionista, incentivando desde o início da graduação o compromisso com as questões sociais. O projeto PET FEIRA-LIVRE se faz de forma continuada, orientando-se pelos pressupostos (comunicação, diálogo e respeito à cultura), que devem atravessar as atividades extensionistas.

Espera-se com essas intervenções, além de levar a informação e promover a troca de experiências, aumentar o alcance de abrangência da Universidade Federal de Viçosa, Campus Florestal-MG, inserindo a população local como participantes ativos da vida acadêmica.

\section{A primeira experiência com o PET FEIRA-LIVRE}

Desde os primórdios das sociedades, acidentes com animais peçonhentos e venenosos são um problema, sendo que, no Brasil, tais acontecimentos se tornaram um sério problema de saúde pública (BOCHNER, 2003). Nesse contexto, detectar fatores de risco, condições hostis e ações que colaborem com esses acidentes, implementando e/ou informando sobre medidas de se prevenir ou controlar tais fatores, podem ser ações no campo da epidemiologia ambiental que contribuam de fato para minimizar os impactos negativos à saúde relacionados ao que se trata (FUNASA, 2002).

Ainda que certos animais, confundidos com animais peçonhentos e/ou venenosos, não ofereçam perigo algum à saúde da população em geral, a falta de conhecimento sobre determinadas espécies pode ocasionar o extermínio indiscriminado de animais inofensivos e também daqueles que, apesar de apresentarem perigo, têm grande importância para o equilíbrio do ambiente natural (MOURA et al., 2010). Dessa forma, existe a preocupação com a saúde da população e também com a conservação desses animais.

Nesse sentido, e levando em consideração as problemáticas apresentadas acima, concluiu-se que utilizar do espaço proporcionado pelo PET FEIRA-LIVRE para tratar desse tema junto à sociedade seria uma boa opção, uma vez que o caráter extensionista do evento permite a relação entre o conhecimento popular e científico, assim, proporcionando um ambiente propício para desmistificar certos conceitos, levantar dados sobre a interação da população com animais peçonhentos e venenosos, além de orientar no sentido da importância desses animais e como agir em casos de acidentes.

Por apresentar características rurais e ser rodeado por extensas áreas de mata, o município de Florestal-MG apresenta alta incidência de animais peçonhentos e venenosos. Portanto, partindo da hipótese de que a população não apresenta total conhecimento sobre as diferenças entre animais venenosos e peçonhentos, quais são estes e sobre por que são importantes, reconheceu-se a necessidade de trabalhar a conscientização da população para a conservação da biodiversidade e, ainda, de oferecer informações corretas sobre como proceder em relação a acidentes. Assim, o primeiro PET FEIRALIVRE, realizado no dia 25 de abril de 2015, teve como tema os Animais Peçonhentos.

O principal objetivo, portanto, foi o de levar informação científica aos moradores de Florestal-MG desmistificando conceitos errôneos e promovendo o contato dos frequentadores da feira livre com alguns animais peçonhentos. O espaço também foi aproveitado para, por meio da aplicação de questionários, compreender como esse evento pode contribuir para o conhecimento das pessoas e qual a importância de atividades em epidemiologia e saúde ambiental de cunho extensionista para o município de Florestal-MG. 


\section{Procedimentos Metodológicos}

Para abrigar a exposição dos materiais bem como dos animais, uma tenda dobrável de alumínio de $3 \times 3 \mathrm{~m}$, foi montada no local do evento, pelos próprios alunos integrantes do PET (Figura 1). A tenda foi posicionada próxima a outras barracas e em local estratégico que facilitou a visualização da exposição.

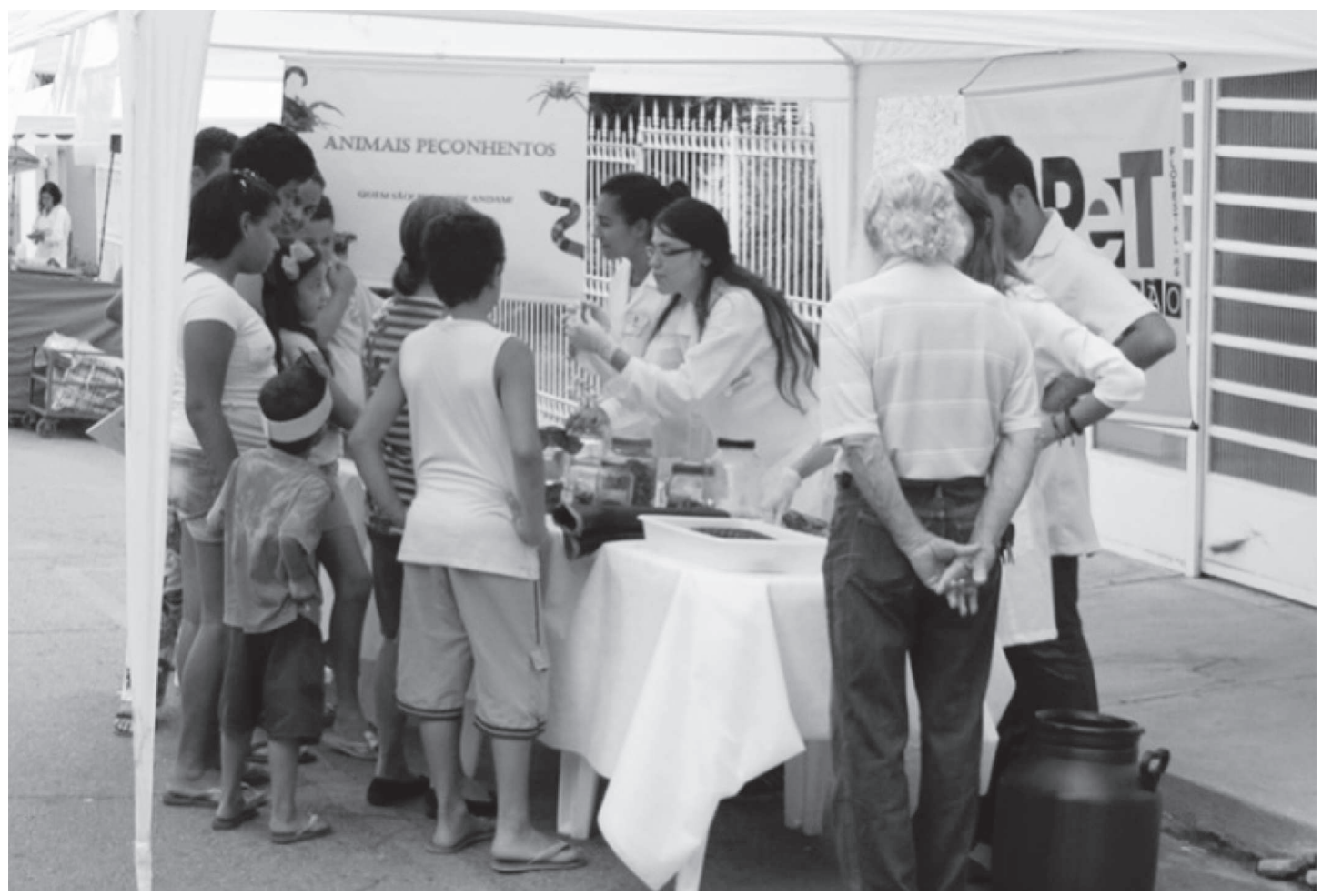

Figura 1 - Feirantes e moradores locais visitando a exposição sobre animais peçonhentos realizada pelo PET/EDUCAÇÃO. Fonte: Arquivos do programa PET/EDUCAÇÃO UFV-CAF. 2015.

Foram utilizados animais fixados da Coleção Didática Zoológica do Campus UFV Florestal, bem como animais capturados vivos para demonstração ${ }^{7}$. Os animais vivos foram devidamente alocados e devolvidos ao seu ambiente natural após a realização do evento.

Durante a realização do evento, algumas orientações eram dadas aos visitantes da exposição. Estas orientações foram divididas de forma que cada estudante apresentasse um determinado grupo de animais. Inicialmente os visitantes eram questionados sobre a diferença entre animais peçonhentos, venenosos e não-venenosos, sendo essa diferença esclarecida após serem ouvidas as respostas. Posteriormente cada grupo de animais era apresentado utilizando de seus nomes populares assim como foi feito para cada espécie. Nos cartazes afixados pela feira eram disponibilizados os nomes científicos de cada espécie apresentada na exposição. As características principais de cada grupo eram abordadas, bem como sua condição como peçonhento, venenoso ou não-venenoso. Em seguida eram passadas orientações a respeito de como conviver com animais peçonhentos e de como se prevenir contra acidentes, envolvendo os visitantes e os estudantes num diálogo participativo. Essa metodologia foi baseada na proposta de pesquisa-ação relatada por Thiollent (1996), uma vez que teve como objetivos resolver problemas práticos relacionados à saúde e conservação ambiental, estimular a tomada de consciência a respeito desses temas e produzir conhecimento sobre como a comunidade pesquisada se coloca sobre esses assuntos.

Numa tentativa de quantificar a importância desse evento para o objetivo proposto, elaborouse um questionário estruturado, com oito perguntas, que foi aplicado a um grupo de pessoas que visitou a exposição e também a um grupo que não visitou a tenda do evento. As pessoas que visitavam a exposição eram submetidas ao questionário no momento da apresentação. Sobre as pessoas que não compareceram ao local do evento, alguns alunos participantes do projeto transitaram pela feira livre a fim de aplicar o questionário a esse grupo. Foi utilizado para análise dos resultados o 
método comparativo, reconhecido como instrumento de análise na pesquisa social empírica. Esse método realiza comparações entre diferentes grupos com a finalidade de verificar similaridades e divergências entre estes (SCHNEIDER \& SCHIMITT, 1998).

No final de cada apresentação, uma cartilha informativa ${ }^{8}$, cedida pela Fundação Ezequiel Dias (FUNED), foi disponibilizada para os visitantes.

Durante todo o processo, procurou-se manter a participação ativa do espectador a fim de tornar a experiência dinâmica e propícia para a troca de conhecimentos.

\section{Resultados}

Organizando os dados, constatou-se todos os níveis de escolaridade presentes no questionário aplicado aos frequentadores da feira livre, embora o ensino superior incompleto tenha apresentado maior número. Esse resultado deve-se à inserção da Universidade Federal de Viçosa no município de Florestal-MG. Também foi observado que $87 \%$ das pessoas que responderam o questionário residem na zona urbana.

Os dados da figura 2 mostram o resultado da pergunta “Qual (is) destes animais é(são) peçonhento(s)?". As pessoas que tiveram acesso à tenda de animais peçonhentos conseguiram identificar com maior clareza quais animais possuem peçonha, em comparação aos que não tiveram acesso às informações da tenda. Assim, foi confirmada nossa hipótese de que a população Florestalense, em geral, confunde esses animais, o que pode gerar problemas quanto à conservação desses grupos. Conhecer esses grupos, quais são os perigos que eles oferecem ou não e como conviver com eles é um passo importante. Além disso, também é o que se buscou com a realização desse evento. Acredita-se que uma boa relação é a articulação entre o conhecimento científico gerado pela comunidade acadêmica e o popular oferecido pela população Florestalense, pois fica mais simples quando a ciência faz sentido no contexto cultural e social do indivíduo.

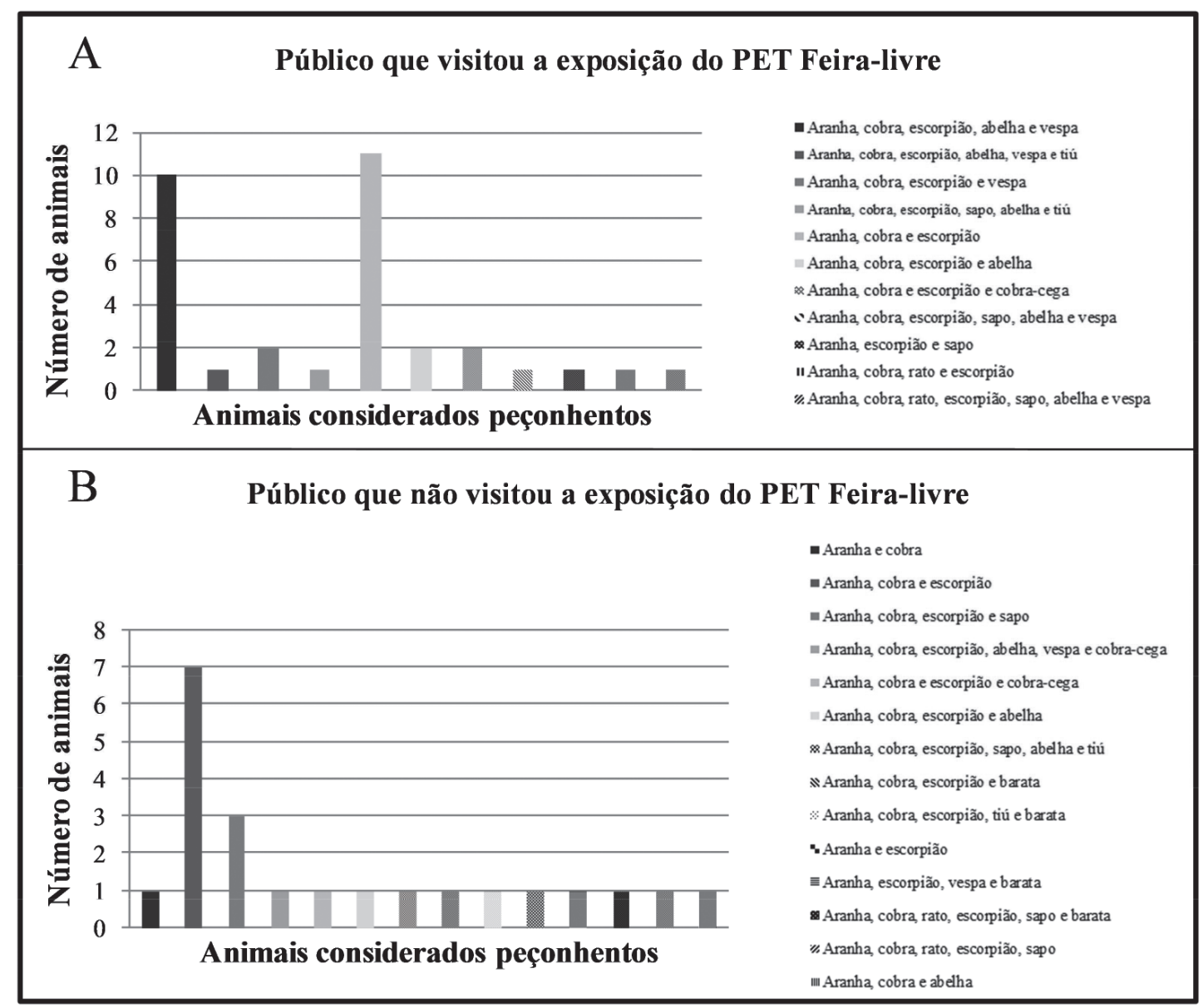

Figura 1 - Animais considerados peçonhentos pela comunidade da feira livre de Florestal-MG, que visitaram (A) ou não visitaram(B) a tenda do PET FEIRA-LIVRE. 
Ao analisar a pergunta: "Qual a sua reação ao encontrar um animal peçonhento em casa? Percebeu-se que a maioria das respostas relata "a captura e a soltura do animal em outro local". Porém, as opções "matar o animal e chamar órgão competente (IBAMA, Universidade e Polícia ambiental)" também tiveram grandes índices de resposta. Esses índices nos preocuparam, principalmente no que ser refere à conservação desses grupos, uma vez que cobras, aranhas e escorpiões, por exemplo, possuem grande importância ecológica no controle de roedores e insetos.

Na pergunta: "Em caso de acidente com animal peçonhento qual o procedimento adotado?" Observou-se que $85 \%$ das pessoas recorrem ao atendimento médico e $15 \%$ utilizam torniquete no local da picada, usam plantas medicinais ou não fazem nada. Não foi encontrada nenhuma relação ao procedimento adotado em caso de acidente com animais peçonhentos, no que se refere ao sexo, idade, local da residência (rural ou urbana) e escolaridade. No entanto, verificou-se que $75 \%$ das pessoas que utilizam torniquetes e plantas medicinais não tiveram acesso às informações da tenda do PET FEIRA-LIVRE. Esse último procedimento (plantas medicinais) não condiz com o que diz a literatura sobre como proceder. No caso de acidentes com animais peçonhentos, lavar com água e sabão o local da picada, usar o torniquete ou compressa com água morna e principalmente tentar capturar o animal para identificação são os principais procedimentos indicados (FUNASA, 2001).

Foi observado ainda, que $69 \%$ dos entrevistados nunca tiveram acidentes com animais peçonhentos. Porém, 31\% das pessoas entrevistadas relataram já ter sofrido algum acidente, sendo o escorpião (53\%) o de maior ocorrência. Isso pode ocorrer em função do elevado número de terrenos baldios com entulhos presentes por toda a cidade, que formam abrigos para esses animais.

Em relação à pergunta "Quais medidas você adota para prevenir acidentes com animais peçonhentos em casa ou no trabalho?", podemos verificar na Tabela 1 que 95\% dos entrevistados adotam pelo menos uma medida de prevenção, sendo as principais relatadas: "Evitar o acumulo de lixo e entulho"; "Examinar sapatos, roupas, toalhas antes do uso"; e "Manter berços e camas afastados da parede". Tais procedimentos adotados, vão ao encontro do que diz a literatura a respeito da profilaxia para animais peçonhentos.

Tabela 1 - Respostas dos frequentadores da Feira Livre de Florestal-MG, sobre as medidas para se prevenir acidentes com animais peçonhentos em casa ou no trabalho - 2015

\begin{tabular}{lc}
\hline \multicolumn{1}{c}{ Opção de medida preventiva } & Resposta apontada (\%) \\
\hline Evitar o acúmulo de lixo e entulho. & $9 \%$ \\
Examinar sapatos, roupas, toalhas antes do uso. & $4 \%$ \\
Evitar o acúmulo de lixo e entulho; Examinar sapatos, roupas, toalhas antes do uso. & $22 \%$ \\
Evitar o acúmulo de lixo e entulho; Não manusear animais peçonhentos. & $9 \%$ \\
Evitar o acúmulo de lixo e entulho; Manter berços e camas afastados da parede. & $3 \%$ \\
Evitar o acúmulo de lixo e entulho; Examinar sapatos, roupas, toalhas antes do uso; & $3 \%$ \\
Manter berços e camas afastados da parede. & \\
Evitar o acúmulo de lixo e entulho; Não manusear animais peçonhentos; Examinar & $5 \%$ \\
sapatos, roupas, toalhas antes do uso. & $2 \%$ \\
Evitar o acúmulo de lixo e entulho; Manter berços e camas afastados da parede; Outros. & $2 \%$ \\
Evitar o acúmulo de lixo e entulho; Não manusear animais peçonhentos; Examinar & \\
sapatos, roupas, toalhas antes do uso; Outros. & $2 \%$ \\
Evitar o acúmulo de lixo e entulho; Examinar sapatos, roupas, toalhas antes do uso; & \\
Manter berços e camas afastados da parede; Outros. & $11 \%$ \\
Evitar o acúmulo de lixo e entulho; Não manusear animais peçonhentos; Examinar & \\
sapatos, roupas, toalhas antes do uso; Manter berços e camas afastados da parede. & $2 \%$ \\
Evitar o acúmulo de lixo e entulho; Utilizar perneiras; Não manusear animais & \\
peçonhentos; Examinar sapatos, roupas, toalhas antes do uso; Outros. & \\
Evitar o acúmulo de lixo e entulho; Utilizar perneiras; Não manusear animais peçonhentos; & \\
Examinar sapatos, roupas, toalhas antes do uso; Manter berços e camas afastados da parede. & $2 \%$ \\
Nenhuma & $5 \%$ \\
\hline
\end{tabular}

Fonte: Dados retirados dos questionários aplicados pelo PET/EDUCAÇÃO durante o PET FEIRA-LIVRE 


\section{Considerações finais}

Com a realização do primeiro PET FEIRA-LIVRE, verificou-se que a feira livre é um espaço amplo para trocas de experiências em epidemiologia e saúde ambiental, sobretudo por abranger um público com características socioculturais distintas.

Em relação ao tema animais peçonhentos, percebeu-se que a maior dificuldade dos frequentadores da feira livre era diferenciar animais peçonhentos, animais venenosos e animais não venenosos. Com a realização da exposição e, por meio das orientações passadas com base nas respostas obtidas, observou-se que ficou nítida a diferenciação desses animais. Conhecer esses grupos, quais são os perigos que eles oferecem ou não e como conviver com eles é um passo importante não só na prevenção de acidentes, mas também na melhor convivência entre a população e os animais do entorno.

Desse modo, o evento junto à feira livre possibilitou a troca de conhecimento científico e popular entre a comunidade acadêmica e Florestalense. Nesse sentido, esse projeto contribui para uma mudança social na vida do discente, pelo fato de que a feira livre é um espaço privilegiado (onde existem agrupamentos culturais que se entrelaçam), bastante valorizado por seus atores sociais e que se configura como disseminador de atividades de extensão em epidemiologia e saúde ambiental.

\section{Fontes de Financiamento}

Agradecemos ao FNDE pelo financiamento das atividades realizadas (bolsas para os petianos e tutor) pelo PET/EDUCAÇÃO da Universidade Federal de Viçosa, Campus Florestal.

\section{Agradecimentos}

Agradecemos a comunidade Florestalense pela participação no evento PET FEIRA-LIVRE, à senhora Cássia, organizadora da Feira Livre de Florestal- MG por ter viabilizado o evento, aos petianos Bárbara A. de Morais, Carla G. Mariana, Ramon L. Fernandes, Sarah V. Miranda e Ystheilon S. Pereira pela colaboração, à Coleção Didática Zoológica da UFV-Florestal por ter cedido os animais, à Fundação Ezequiel Dias (Funed) pela disponibilização da cartilha informativa, e à Universidade Federal de Viçosa, Campus Florestal- MG pelo apoio.

\section{Referências Bibliográficas}

BAPTISTA, G.C.S.; COSTA-NETO, E.M.; VALVERDE, M.C.C. Diálogo entre concepções prévias dos estudantes e conhecimento científico escolar: relações sobre os Amphisbaenia. Revista IberoAmericana de Estudos em Educação, v.47, n.2, p. 1-16, 2008.

BOCHNER, R. Acidentes por animais peçonhentos: aspectos históricos, epidemiológicos, ambientais e sócioeconômicos. Tese de Doutorado. Orientada pelo professor Cláudio José Struchiner, Escola Nacional de Saúde Pública Sérgio Arouca, 2003. Disponível em: <http://www.arca.fiocruz.br/bitstream/ icict/1341/1/Acidentes_por_animais_Peconhentos-Rosany_Bochner.pdf $>$. Acesso em: 8 out. 2015.

FELDER, R. M.; BRENT, R. Learning by Doing. Chemical Engineering Education, v.37, n.4, p.282-283, 2003.

FREIRE, P. Extensão ou comunicação? São Paulo, Paz e Terra: 2006.

FUNDAÇÃO NACIONAL DE SAÚDE - FUNASA. Manual de diagnóstico de tratamento de acidentes por animais peçonhentos. Brasília, Ministério da Saúde: 2001...

FUNDAÇÃO NACIONAL DE SAÚDE - FUNASA. Vigilância Ambiental em Saúde. Brasília, Ministério da Saúde: 2002.

LIMA J. S.; MARTELLI JÚNIOR H.; MARTELLI D. R. B.; SILVA M. S.; CARVALHO S. F. G. Perfil dos acidentes ofídicos no norte do Estado de Minas Gerais, Brasil. Revista da Sociedade Brasileira de Medicina Tropical. v.42, n.2, p. 561-564, 2009.

MASCARENHAS, G.; DOLZANI, M. C. S. Feira Livre: Territorialidade Popular e cultura na metrópole contemporânea. Ateliê Geográfico. v.2, n.2, p.72-87, 2008. 
MOURA, M. R.; COSTA, H. C.; SÃO-PEDRO, V. A.; FERNANDES, V. D.; FEIO, R. N. O relacionamento entre pessoas e serpentes no leste de Minas Gerais, sudeste do Brasil. Biota Neotropica. v.10, n.4, p. 133-141, 2010.

OLIVEIRA, H. F. A.; COSTA, C. F.; SASSI, R. Relatos de acidentes por animais peçonhentos e medicina popular em agricultores de Cuité, região do Curimataú, Paraíba, Brasil. Revista Brasileira Epidemiológica. v.16, n.3, p.633-643. 2013.

QUIRINO, M. A. S.; SILVA, G. L.; MAGALHÃES, J. D. R.; SANTOS, E. M. Educação ambiental como medida preventiva e cuidados com acidentes ofídicos na unidade acadêmica de Serra Talhada. IX Jepex, 2009. Resumos. Disponível em: <http://www.eventosufrpe.com.br/eventosufrpe/jepex2009/cd/ resumos/R0710-1.pdf>. Acesso em: 19 out. 2015.

RONZELli, P. J. A extensão universitária. Portal Mackenzie. Disponível em: <http:// www.mackenzie.br/extensao_universitaria.98.html>. Acesso: 18 abr. 2015.

SCHNEIDER, S.; SCHIMITT, C. J. O uso do método comparativo nas Ciências Sociais. Cadernos de Sociologia. v.9, n.1, p. 49-87, 1998.

SILVA, E. W. Extensão universitária no Rio Grande do Sul - Concepções e práticas. Tese de Doutorado. Orientada pela professora Clarissa Eckert Baeta Neves, Universidade Federal do Rio Grande do Sul, 2003. Disponível em: <https://www.lume.ufrgs.br/bitstream/handle/10183/3780/ 000392869.pdf?sequence=1>. Acesso em: 15 abr. 2015.

THIOLLENT, M. Metodologia da pesquisa-ação. São Paulo, Cortez: 1996.

\footnotetext{
${ }^{7}$ Sapo-boi (Rhinella schneideri); Aranha armadeira (Pheneutria nigriventer); Calango (Tropidurus torquatus).

${ }^{8}$ Disponível em: http://funed.mg.gov.br/wp-content/uploads/2010/03/cartilha.pdf.
} 